\title{
Sport and exercise headache: Part 1. Prevalence among university students
}

\author{
Stephen J. Williams BMed Sci and Hitoshi Nukada MD \\ Department of Medicine, University of Otago Medical School, Dunedin, New Zealand
}

\begin{abstract}
Sport- and exercise-related headaches have been recognized over the last 20 years, but their prevalence is unknown. A nine-page questionnaire was used to study the prevalence of sports headaches among two contrasting populations of Otago University students: medical students $(n=178)$ and physical education students $(n=190)$. Both populations had a similar response rate of approximately $80 \%$. It was found that $35 \%$ of respondents had experienced sport- and exercise-related headaches among the two populations, with similar rates for men and women seen in both. Comparision of the two populations showed no significant difference in the rate of sports headache among women, whereas the men physical education students has a significantly higher rate of sports headache than the men medical students. A high frequency of trauma-related headaches in contact sports accounted for this higher rate among the men physical education students. This study demonstrated that sportand exercise-related headaches are a common problem among university students.
\end{abstract}

Keywords: Epidemiology, headache, sports headache, sports neurology, university student

It is well known that almost any sport can cause neurological injuries involving any level of the nervous system. However, it should be emphasized that sport and exercise also induce a wide variety of non-traumatic neurological problems including headache. Sport- and exercise-related headache is an important aspect of sports neurology and sports medicine in general, although it has received little attention and is often misdiagnosed or underreported $^{1}$. Hippocrates was perhaps the first to describe sports headache as a true clinical entity: 'One should be able to recognise those who have headache from gymnastics exercise, or running, or walking, or hunting, or any other unreasonable labour, or from immoderate venery (Hippocrates) ${ }^{\prime 2}$. Individual cases of sports headache have been documented in the literature ${ }^{1,3,4}$. Epidemiological study of sports headache, however, has not previously been undertaken. The objectives of the study

Address for correspondence: Dr Hitoshi Nukada, Department of Medicine, University of Otago Medical School, PO Box 913, Dunedin, New Zealand

(C) 1994 Butterworth-Heinemann Ltd 0306-3674/94/020090-06 were: (1) to establish the prevalence of sports headache using the questionnaire in two defined populations, medical students and physical education students at the University of Otago; and (2) to make comparisons between these two groups. In selecting the sample population two factors were considered. First, any survey investigating the frequency of headache must be based on a defined population ${ }^{5}$. Second, the defined population must be suitable for the study, since the prevalence of sports headache is unknown. Therefore the populations were chosen on the basis that they would hopefully exhibit subjects suffering from sports headache. The rates of headache in the study fitted the description of headache sufferers who have experienced sportsrelated headache and other headache at some stage of their lives.

\section{Methods}

Two sources of sports headache subjects were established among students of the University of Otago: in the medical student population, the third-year medical student class consisting of 178 students; and in the physical education (PE) student population, the Sports and Leisure studies class consisting of 190 students. The questionnaire was administered to the two populations in a lecture theatre. Although administration of the questionnaire was not random as it allowed a high response rate over a short period of time with the questionnaire easily collected.

The questionnaire was designed so that subjects could follow it through in an easy logical order, requiring only a short period of time. Questions required choice, the respondent placing a tick in the appropriate box. Written answers were kept to a minimum and were clearly specified when expected. The framework of the questionnaire was based on the standard history-taking of headache, providing information on the onset, time course, characteristic features and associated symptoms of the headache ${ }^{6}$, adding questions specific to sport and exercise headache. The questionnaire was organized into three sections: (1) general questions; (2) questions on non-sports-related headache; and (3) questions on sports-related headache, i.e. any headache suffered during or immediately after sport or exercise. Questions on the prevalence of headache were not confined to those headaches in the year before the 
study. The section on sports headache consisted of 29 questions covering five categories: (1) precipitation of the sports headache; (2) temporal relationship; (3) associated symptoms; and (4) associated factors. All answers selected by respondents corresponded to numerical values that were then coded. The raw data were collected and verified by Data Preparations at the Otago University Computing Centre.

The SPSSX statistical package (SPSS, Chicago, Illinois, USA) on the VAX computer (Digital Equipment, Maynard, Massachusetts, USA) was employed to interpret the data. The Frequencies and Crosstabs programs were used to produce a table of frequency counts and percentages for variables and tables of discrete data groups from two or more variables. The $\chi^{2}$ test was used to test for significant differences between the individual cells in the table. The continuity correction was usually quoted except where a cell of fewer than five cases existed; in this situation Fisher's exact test was used. Results were deemed significant where $P<0.05$.

\section{Results}

The third year medical class numbers 178 students, of whom 144 completed the questionnaire, giving a response rate of $80.9 \%$. The PE Sports and Leisure class contains 190 students, of whom 151 completed the questionnaire, giving a response rate of $79.5 \%$. The two groups established were of a similar age and were predominantly single, but there are some differences in the distribution of the sexes (Table 1). Sports-related headaches of any type were experienced by 40 students in the medical student population (28\%) and 63 students in the PE student population $(42 \%)$, making the overall rate of sport and exercise headache among these students 35\% (Table 2). The overall rate of sports headache was 35\%

Table 1. Demographic variables of two survey groups of Otago University students

\begin{tabular}{lccc}
\hline Variables & $\begin{array}{c}\text { Medical } \\
\text { population }\end{array}$ & $\begin{array}{c}\text { Physical } \\
\text { Education } \\
\text { population }\end{array}$ & Total \\
\hline Number & 144 & 151 & 295 \\
Mean age & $21.4(2.8)$ & $20.3(1.9)^{*}$ & 20.9 \\
Age distribution & $19-33$ & $17-34$ & $17-34$ \\
Men & $86(60 \%)$ & $61(40 \%)$ & $147(50 \%)$ \\
Women & $58(40 \%)$ & $90(60 \%)$ & $148(50 \%)$ \\
\hline
\end{tabular}

*Values are mean(s.d.) in both men and women (Table 2). The overall rate of non-sports-related headache in the two populations was significantly greater in women $(62 \%)$ than in men $(45 \%)(P<0.004)$.

When comparison between the two populations was made, both men and women PE students showed a greater frequency of sports-related headache. However, the only significant difference produced was between the men PE students and the men medical students $(P<0.02)$. Comparison between the two populations for both men and women showed no significant difference in past or family history of epilepsy, hypertension, migraine, alcohol or caffeine consumption. Subjects were asked how they perceived their own fitness (four grades from poor to excellent). Both men and women PE students rated themselves significantly fitter than medical students $(P<0.0002)$, although among the sports headache population no significant difference in perceived fitness was found. The weekly activity of subjects was indirectly measured by the number of sports or exercises each individual regularly participated in each week. The PE students of both sexes were significantly more active than the medical student population $(P<0.0001)$. Both $\mathrm{PE}$ men and women played a significantly greater number of contact sports, e.g. rugby football, than the medical student population $(P<0.0001)$, and PE students suffering from sports headache played significantly more contact sports than medical students $(P<0.0003$ for men; $P<0.03$ for women $)$. Although the women populations in the two groups showed no significant difference in their rates of injury, the men PE population suffered a significantly higher incidence of head, neck and back injuries than the men population $(P<0.0003)$. However, no significant medical correlation was found between such injuries and increased risk of experiencing sports headache. The characteristics of sports headaches in each population were similar. No significant differences were seen in the time course, characteristic features and associated symptoms. The only significant difference was in the initiation of the sports headache. The high rate of involvement in contact sport among men PE students was reflected by a high number of sports headaches initiated by head trauma (60\% of sports headache in men PE students compared with $30 \%$ of those in men medical students).

Among both the PE and medical students, a large number of sports headache subjects also noticed non-sports headache. Of the men, $67 \%$, and $75 \%$ of the women, who had experienced sports headache

Table 2. Prevalence of sports- and non-sports-related headaches among Otago University students

\begin{tabular}{|c|c|c|c|c|c|c|c|c|c|}
\hline \multirow[b]{2}{*}{ Type of headache } & \multicolumn{3}{|c|}{ Medical population } & \multicolumn{3}{|c|}{ Physical education population } & \multicolumn{3}{|c|}{ Overall } \\
\hline & $\begin{array}{c}\text { Men } \\
(\mathrm{n}=86)\end{array}$ & $\begin{array}{l}\text { Women } \\
(\mathrm{n}=58)\end{array}$ & $\begin{array}{c}\text { Total } \\
(\mathrm{n}=144)\end{array}$ & $\begin{array}{c}\text { Men } \\
(n=61)\end{array}$ & $\begin{array}{l}\text { Women } \\
(\mathrm{n}=90)\end{array}$ & $\begin{array}{c}\text { Total } \\
(\mathrm{n}=151)\end{array}$ & $\begin{array}{c}\text { Men } \\
(n=147)\end{array}$ & $\begin{array}{l}\text { Women } \\
(n=148)\end{array}$ & $\begin{array}{c}\text { Total } \\
(\mathrm{n}=295)\end{array}$ \\
\hline $\begin{array}{l}\text { Sports-related headache } \\
\text { Non-sport-related headache }\end{array}$ & $\begin{array}{l}23(27 \%) \\
42(49 \%)\end{array}$ & $\begin{array}{l}17(29 \%) \\
39(67 \%)\end{array}$ & $\begin{array}{l}40(28 \%) \\
81(63 \%)\end{array}$ & $\begin{array}{l}28(46 \%) \\
24(39 \%)\end{array}$ & $\begin{array}{l}35(39 \%) \\
53(59 \%)\end{array}$ & $\begin{array}{l}63(42 \%) \\
77(51 \%)\end{array}$ & $51(35 \%)$ & $52(35 \%)$ & $103(35 \%)$ \\
\hline
\end{tabular}


suffered from at least one other type of headache $(P<0.0002$ for men and $P<0.02$ for women). The lower significance in women was due to the much higher frequencies of non-sports-related headache noticed by the overall population of women. Conversely subjects reporting non-sports headaches showed the same tendency to display a higher rate of sports headache than those subjects not experiencing non-sports-related headache, $51 \%$ of men and $42 \%$ of women experiencing non-sports headache, also suffering from sports headache. In total, 158 subjects reported non-sports-related headache, including 20 cases diagnosed as migraine and 15 cases of tension headache. Of non-sports migraine sufferers $65 \%$ also experienced sports-related headache, but this was not significantly greater in comparison with the overall rate of non-sports-related headache among sports headache sufferers. The occurrence of spontaneous migraine in conjunction with sports migraine is detailed in Part 2 of this study. Subjects were also asked if exercise or sport altered the frequency or quality of their non-sports-related headache. Of 151 students $40(26 \%)$ answered 'yes' 19 men and 21 women. Non-sports-related headache improved in a majority of them $(73 \%)$, but seven subjects $(17 \%)$ described their headache as worsened by exercise.

\section{Discussion}

The prevalence of sport- and exercise-related headache was determined in medical and PE students of Otago University. We found that approximately one-third of students had experienced sport and exercise headache. Although sports headache was most common among men PE students, overall men and women revealed a similar rate of sportsrelated headache. The questionnaire is the sole source of information in the study and is subject to error. The largest sources of error occur in the design of the questionnaire and the responses of the recipients. The questionnaire was constructed from the best available sources. It was administered on one occasion only - an efficient process providing a high response rate. Non-response bias was introduced into the study by $19 \%$ of medical students and $20.5 \%$ of PE students who failed to fill in the questionnaire. It is difficult to assess the validity of information gathered in the present study, since no previous questionnaires on sports headache are available and the prevalence of sports headache has never been previously investigated. The frequency of nonsports-related headache in the present study, however, was greater in women than in men, as reported in the literature ${ }^{7}$.

Comparison of the medical and PE student populations was undertaken at various levels. Both populations had a similar response rate of approximately $80 \%$, and were of similar age and marital status. The PE men and women had a higher rate of sports-related headache and were perceived to be more active and physically fitter than the medical students, prompting the hypothesis that a more active population would have a higher rate of sports headache. However, only the men PE students showed a significantly higher rate of sports headache than the men medical students. A higher rate of sports headache in the PE group than in the medical group is more probably due to the fact that $\mathrm{PE}$ students participate more frequently in contact sports. Comparison of those suffering from sports headache in each population revealed that men PE students with sports headache participated in contact sport at a much higher rate; $60 \%$ of the 28 incidences of sports headache in men PE students resulted from head trauma in contact sport compared with $30 \%$ of the 23 men medical students reporting sports headaches. PE men showed a significantly higher rate of head, neck and back injuries, but this factor does not appear to increase significantly the risk of experiencing sports-related headache. Considering that there are $20 \%$ fewer men in the PE population, the high number of sports headaches resulting from contact sport appears to be the significant factor accounting for the higher rate of sports headache in men PE students.

A significant correlation showed sports headache sufferers to have a greater rate of other forms of headache than those without sports headache. The majority of non-sports-related headaches, however, were regarded as mild, troubling the subjects only occasionally. No significant correlation was found between sports headaches and specified types of recognized headaches such as migraine. The relationship between spontaneous migraine and sports migraine is discussed in Part 2 of this study. While a number of subjects indicated stress in conjunction with their sports headache, in others exercise provided relief from stress. The majority experienced an improvement in their headache as a result of exercise, and relief of stress was believed to be the main benefit of the exercise ${ }^{8}$. However, as this was not a random selection, those missing from the population may make the sample not representative of the population.

In conclusion, sport- and exercise-related headache is a common problem among university students. Subjects experiencing sports headache produced a similar distribution among men and women, although it is known that women had a greater frequency of non-sports-related headache. The proposed hypothesis in which the more physically active population would suffer a higher rate of sports headache was not established. This hypothesis may be too simple; for example, increased activity may increase the risk of sports headache, while increased fitness may lower the risk. A careful study looking at actual fitness, the quality and quantity of exercise in the individual along with other factors, is required.

\section{Acknowledgements}

We are grateful to Brian Niven for his assistance in statistical analysis, Dave Gerrard and Mike Flanagan for their advice and discussion, and the staff of the Medicine Department for their help. S.J.W. was supported by the Health Research Council of New Zealand.

\section{References}

1 McCarthy P. Athletes' headaches: not necessarily 'little' problems. Physician and Sportsmedicine 1988; 16: 169-73. 
2 Adams F. The Genuine works of Hippocrates. New York, USA: William Wood 1886: 275.

3 Diamond S, Solomon GD, Freitag FG. Headache in sport. In: Jordan BD, Tsairis P, Warren RF, eds. Sports Neurology, Rockville, Maryland, USA: Aspen 1989: 127-32.

4 Atkinson R, Appenzellar O. Headache in Sport. Seminars in Neurology 1981; 1: 334-43.

5 Waters WE. The Pontypridd headache survey. Headache 1974; 14: 81-90.
6 Hopkins A. A neurologist's approach to patients with headache. In: Hopkins A, ed. Headache: Problems in Diagnosis and Management. Philadelphia, Pennsylvania, USA: WB Saunders 1988: 37-76.

7 Paulin JM, Waal-Manning HJ, Simpson FO, Knight RG. The prevalence of headache in a small New Zealand town. Headache 1985; 25: 147-51.

8 Rapoport A, Sheftell F. Headaches. Runners World 1980; July: 41-43.

\section{Appendix}
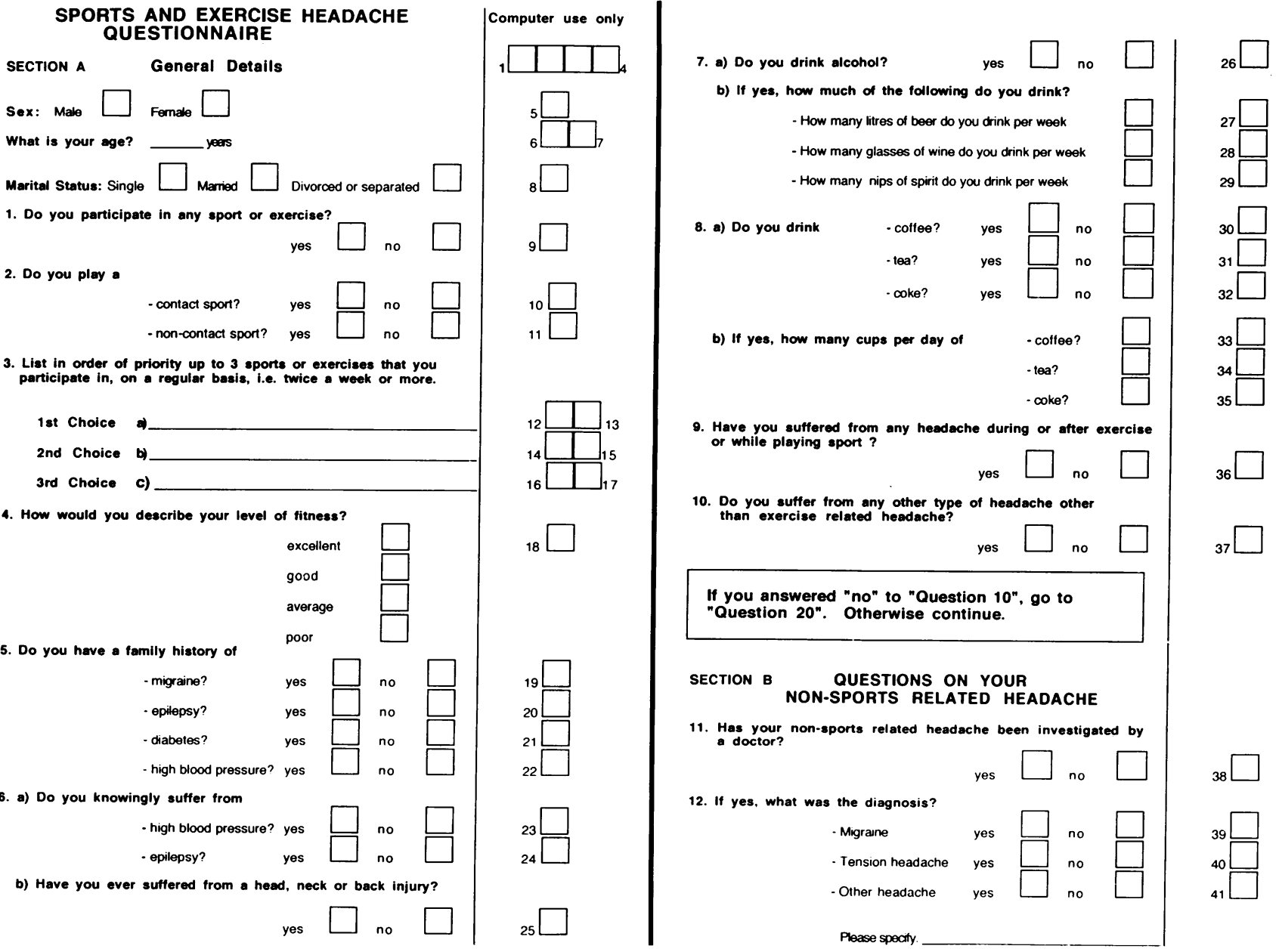
Prevalence of sports headache among university students: S. J. Williams and H. Nukada

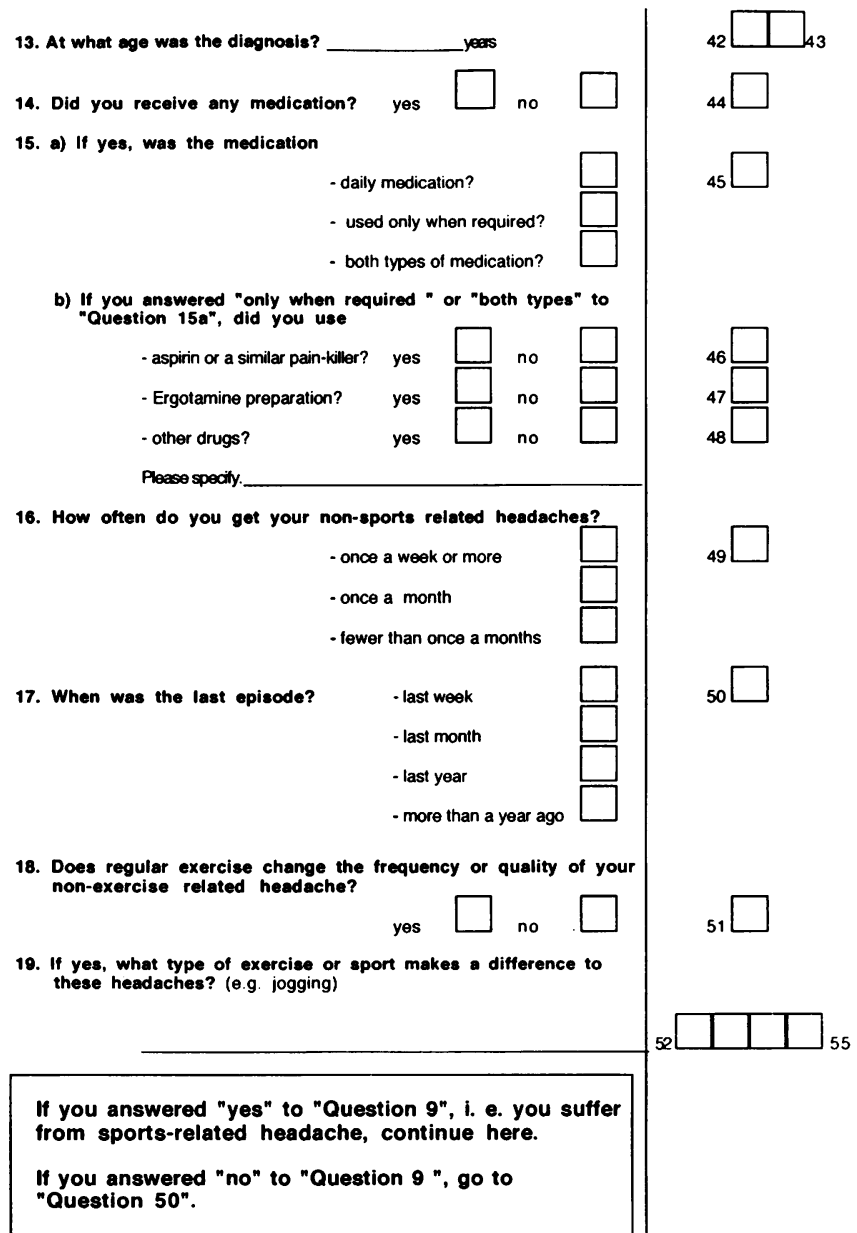

SECTION C
SPOESTIONS ON YOUR
SPORELATED HEADACHE

20. Name the principle sport(s) or exercise that involved the headache

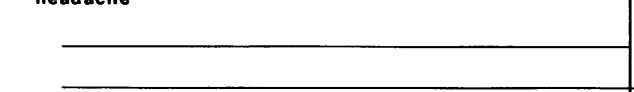

21. How did it occur in relation to the sport or exercise? Tick the appropriate box and also explain how it occurred.

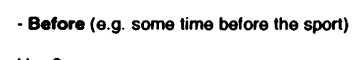

How?

- During (e.g. Irom making a tackle)

How?

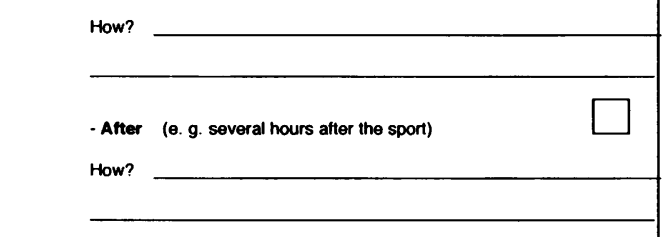

22. a) When did your sports related headaches begin ?:

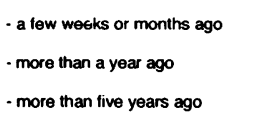

b) What age were you?

23. How frequent are they?

$$
\begin{aligned}
& \text { - every time you play the particular sport } \\
& \text { - on every second or third occasion } \\
& \text { - only occasionally }
\end{aligned}
$$
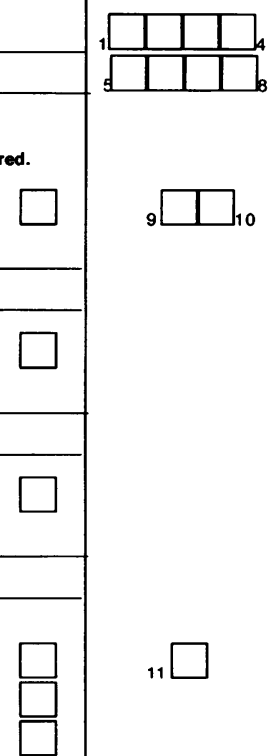

24. How rapid is the onset of your sports related headache?

$$
\begin{aligned}
& \text { - sudden i.e within seconds } \\
& \text { - acute i.e. within minutes } \\
& \text { - gradual i.e hours }
\end{aligned}
$$
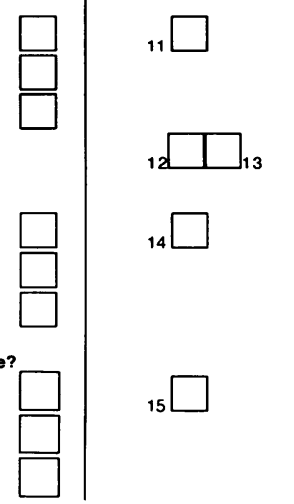

25. a) How long do they last?

-seconds
- minutes
- hours
-all day
- days

b) When was your sports headache the worst?

$$
\begin{aligned}
& \text { - straight away } \\
& \text { - in the middle of the headache } \\
& \text { - at the end } \\
& \text { - throughout the headache }
\end{aligned}
$$

26. How long does it take you to recover from your sports headache?

$$
\begin{aligned}
& \text { - minutes } \\
& \text { - hours } \\
& \text { - after a nights sloep }
\end{aligned}
$$
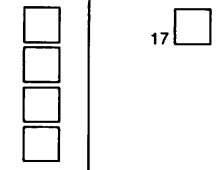

27. Tick the box which best describes the pain of your sports headeche.

$$
\begin{aligned}
& \text { - aching/dull } \\
& \text { - pounding/throbbing } \\
& \text { - splitting } \\
& \text { - burning } \\
& \text { - stabbing } \\
& \text { - sharphightning } \\
& \text { - tight/heaviness }
\end{aligned}
$$$$
\text { - pounding/throbbing }
$$

28. Whereabouts in the head is the pain located?

- all over the head
- across the lorehead
- the back of the head
- always on one side of the head
- on one side of the head or the other
- worse on one side of the head
- unsure of location of the pain

29. Does the pain radiate anywhere else ? yos $\square$ no If yes, please describe.

30. How severe is your average sports related headache? mild (Can easily be ignored.)

moderate (Cannot be ignored,but does not interlere with everyday activity, e.g. you are able to continue your exercise or sport.)

severe (Interteres with most tasks and concentration, .g. you are unable to continue exercise or sport.)

31. How severe is your worst sports related headache? - mild (Can easily be ignored)

- moderate (Cannot be ignored,but does not intertere with everyday activity, e.g. you are able to continue your

severe (Interferes with most tasks and concentration, e.9 are unable to continue exercise or sport )

32.a) Are there any warning symptoms before the sports-related headache begins?

b) If yes, which of the following best describes them?

-blurring of vision

shimmering lights, shapes or colours

numbness or tingling in part of the body

- weakness in any part of the body

stiffness in the neck

- an unusual feeling in the stomach

-any other warning symptom

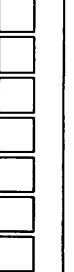

Please specity 
Prevalence of sports headache among university students: S. J. Williams and H. Nukada

33. Describe any symptoms during or after the sports related

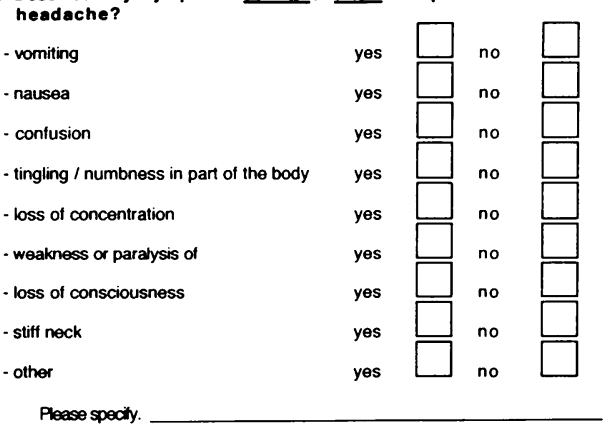

34. What do you do to relieve your sports related headache?

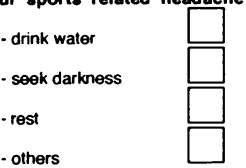

Ploase specity

35. Have you taken any medication for your sports related headache, past or present? yes $\square$ no

36. a) If yes, was the medication

$$
\begin{aligned}
& \text { - daily medication? } \\
& \text { - only when required? } \\
& \text { - both types of medication? }
\end{aligned}
$$
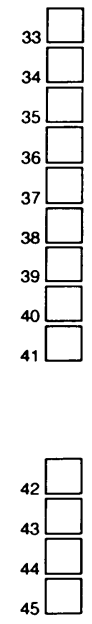

${ }_{44}^{43} \square$

"only when required" to Question 36 did you use

$$
\begin{array}{llll}
\text { - aspirin or a similar pain-killer? yes } & \square \\
\text { - Ergotamine preparation? } & \text { yes } & \square \\
\text { - other drugs? } & \text { yes } & \square
\end{array}
$$$$
\text { Please specity. }
$$
37. a) Have you tried any non-medication therapy for your sports
related headache?

b) If yes, did you try
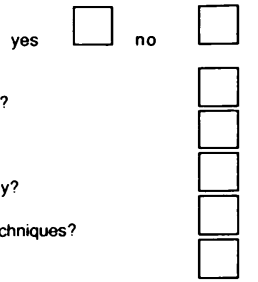

Please specity.

38. a) Have you drunk alcohol the night before any of your sports
related headaches?

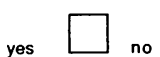

b) If yes,

How many hitres of ber did you drink?

- How many nips of spirit did you drink?
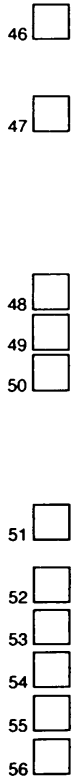

${ }_{47} \square$

49. Did the doctor recommend you to stop playing the sport involving the headache?

$$
\text { yes }
$$

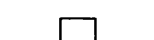

44. Do the headaches effect your work and/or social life?

45. If you have suffered a head, neck or back injury, was this

$$
\text { yes }
$$

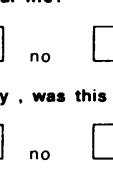

46. Have you consulted a doctor about your sports headaches?

47. What did s/he do?

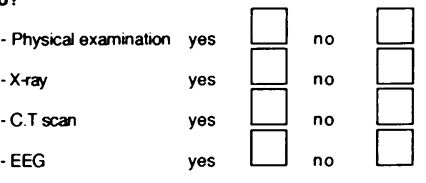

48. a) Did ahe mate a diagnosis?

yes

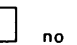

b) If yes, was it - Migraine

- Headache due to a blow to the head

- Headache from over exertion

Other headache

42. Were you under any extra stress before any of your sports
If you have answered the questions on sports headache and/or non-sports related headache, and you are willing to do anothe
possible questionnaire latter in the year, I would very much

possible questionnaire latter in the year, I would very much
appreciate it if you could include your name, address and phone. Name:

Name:

Phone

Thank you

Steve Williams
39. a) Have you drunk any coffee, tea or coke in the 24 hour period

before any of your sports related headaches?

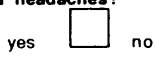

b) If yes, how many cups of

- coftee?

- tea?

- coke?

${ }_{57} \square$

${ }_{60}^{58} \square$

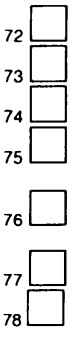

$76 \square$

${ }_{78} \square$

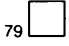

${ }_{69} \square$
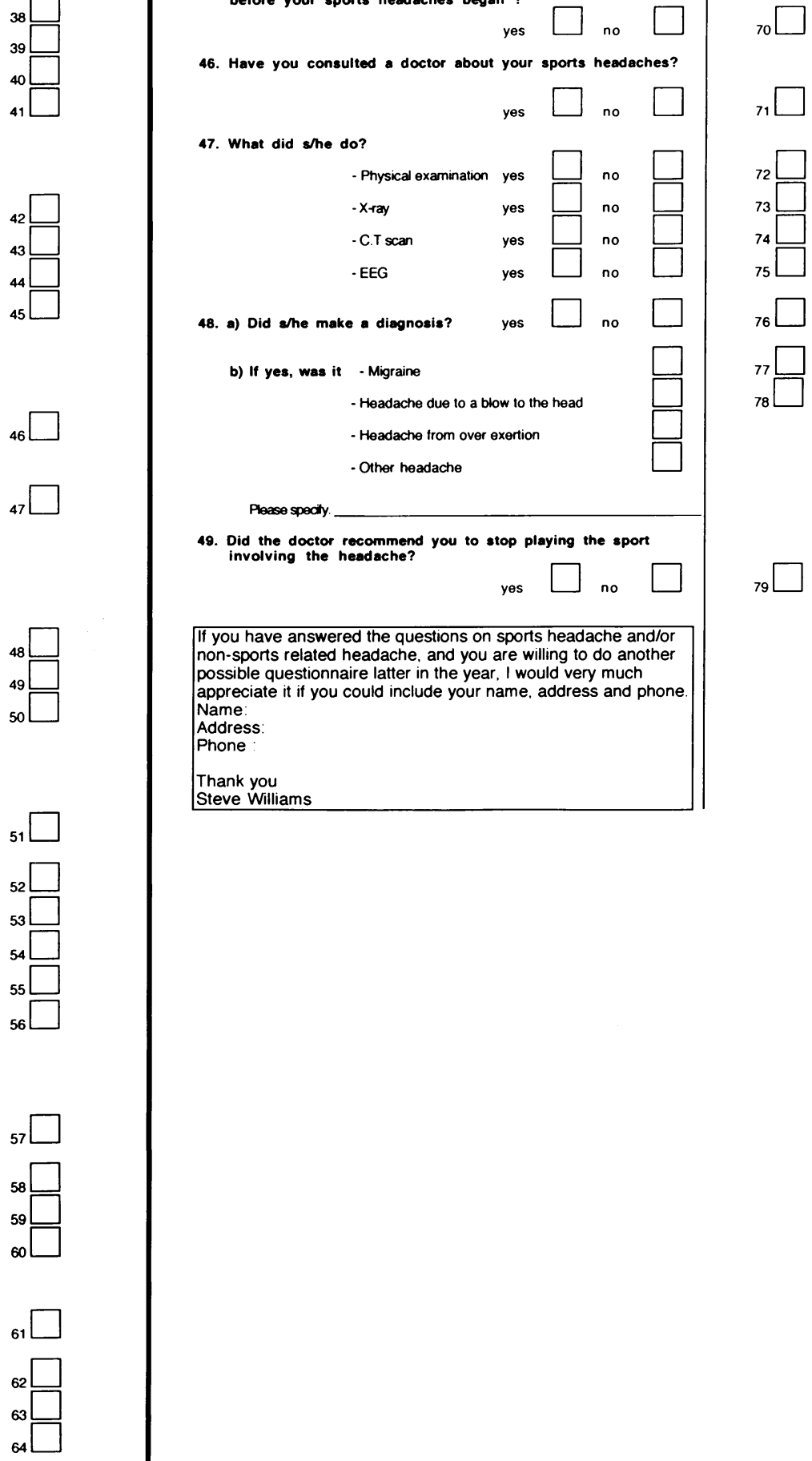

40. Did you use any, prescription, non-prescription or illegal drugs$$
\text { yes } \square \text { no } \square
$$

41. Before the sport or exercise how anxious or nervous were you?
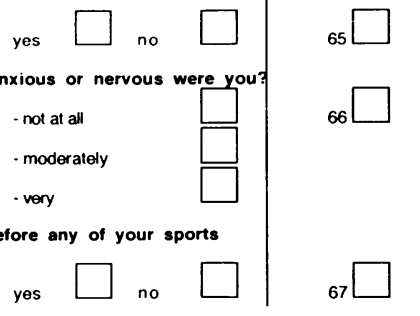
yes $\square$ no $\square \quad{ }_{67} \square$ 